\title{
Left main revascularization with intracoronary lithotripsy guided by optical coherence tomography
}

\author{
Pawel Gasior@, Malwina Nicpon-Smolarek, Andrzej Ochala \\ Division of Cardiology and Structural Heart Diseases, \\ Medical University of Silesia, Katowice, Poland
}

\begin{abstract}
A 75-year-old male previously disqualified from coronary artery bypass grafting was referred to the documented clinic for percutaneous treatment of heavily calcified distal left main (LM) and proximal left anterior descending artery (LAD) lesions. Baseline angiography revealed heavily calcified significant lesion in the distal LM and calcifications in the proximal LAD (Fig. 1A). Due to the large diameter of the coronaries, use of rotational atherectomy was excluded and the patient was qualified for intracoronary lithotripsy (ICL). A transfemoral approach using a $7 \mathrm{~F}$ extra back up guiding catheter was chosen. Pre-procedural optical coherence tomography (OCT) confirmed thick calcifications in the distal LM (minimal lumen diameter [MLD] $3.5 \mathrm{~mm}$ ) and in the proximal LAD (MLD $2.5 \mathrm{~mm}$ ) (Fig. 1B). Subsequently, an ICL catheter $(4.0 \times 12 \mathrm{~mm}$, Shockwave C2, Shockwave Medical Inc.) was
\end{abstract}

successfully delivered to the lesion. Eighty applications (at $4 \mathrm{~atm}$ ) in the LM/LAD were performed, achieving full dilation of the ICL balloon at $6 \mathrm{~atm}$. The OCT images obtained after ICL revealed the presence of calcium cracks in the distal LM and proximal LAD (Fig. 1C). Two drug-eluting stents (Orsiro, Biotronik) were then implanted, $4.0 \times 15 \mathrm{~mm}$ in the LM/LAD and overlapping $3.0 \times 15 \mathrm{~mm}$ in the proximal LAD. Subsequently the proximal optimization technique was performed in the LM using non-compliant balloons ( 4.5 followed by $5.0 \mathrm{~mm}$ at $20 \mathrm{~atm}$.). Angiography revealed good angiographic results of the procedure (Fig. 1D). Final OCT confirmed the luminal gain (final MLD: LM $4.8 \mathrm{~mm}$, LAD $3.0 \mathrm{~mm}$ ) with proper stent strut apposition (Fig. 1E). No periprocedural complications were observed and the patient was discharged 24 hours after the procedure.

Conflict of interest: None declared

Address for correspondence: Pawel Gasior, MD, PhD, Division of Cardiology and Structural Heart Diseases, Medical University of Silesia, ul. Ziołowa 45, 40-635 Katowice, Poland, tel: +48 600429 867, +48 32 2523930, fax: +48 32 2523930, e-mail: p.m.gasior@gmail.com

Received: 9.03.2020

Accepted: 1.07.2020

This article is available in open access under Creative Common Attribution-Non-Commercial-No Derivatives 4.0 International (CC BY-NC-ND 4.0) license, allowing to download articles and share them with others as long as they credit the authors and the publisher, but without permission to change them in any way or use them commercially. 


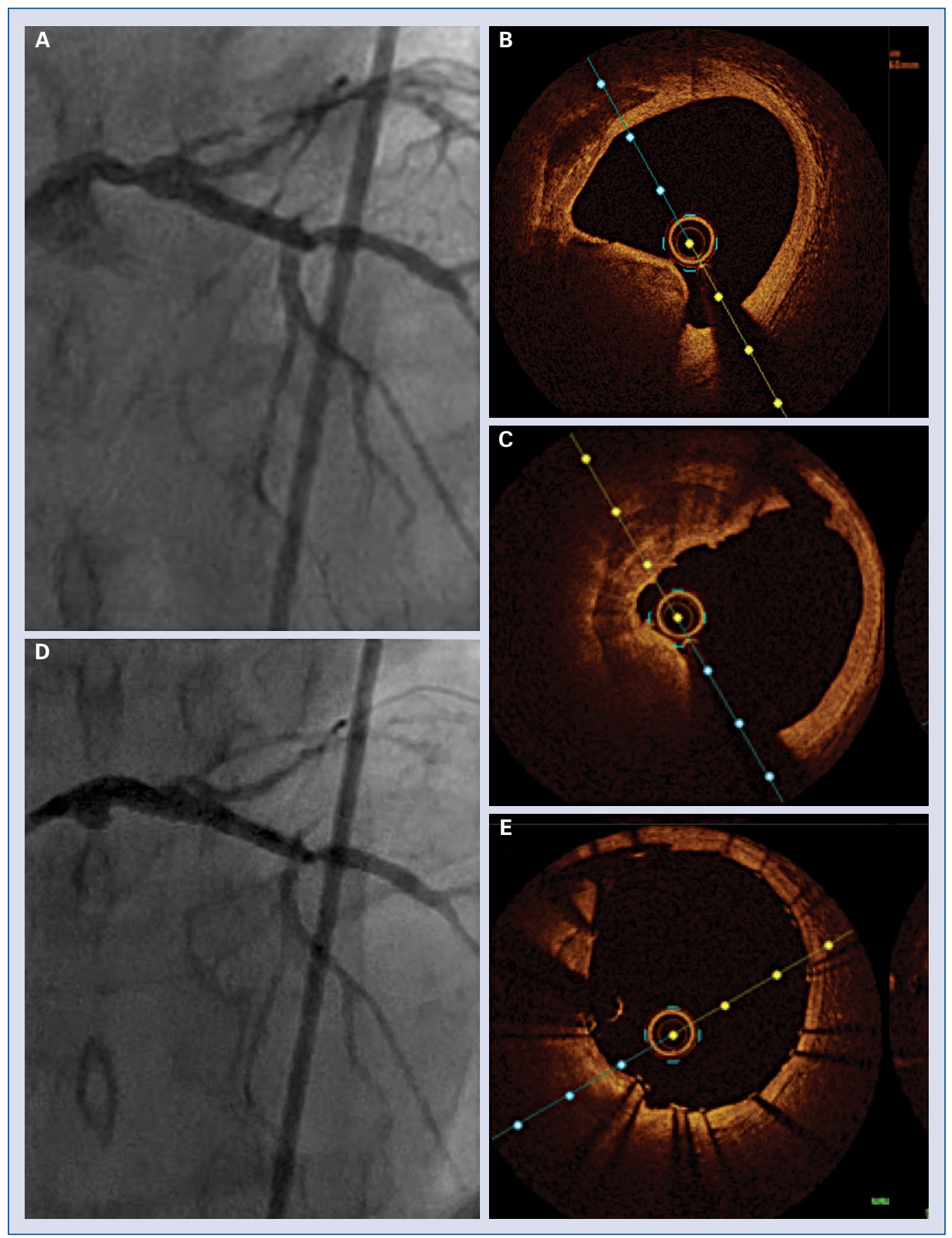

Figure 1. Baseline angiography revealed significant calcified stenosis in the distal left main (LM) and proximal left anterior descending artery (LAD) (A). Pre-procedural optical coherence tomography (OCT) revealed a thick calcium presence (B). OCT after lithotripsy demonstrated cracks in the calcified plaque (C). Angiography after stent implantation showed a good angiographic outcome (D). Final OCT confirmed the luminal gain with proper stent strut apposition (E). 